\title{
Review Article \\ Recent Development in Chemical Depolymerization of Lignin: A Review
}

\author{
Hai Wang, ${ }^{1}$ Melvin Tucker, ${ }^{2}$ and Yun $\mathrm{Ji}^{1}$ \\ ${ }^{1}$ Department of Chemical Engineering, University of North Dakota, Grand Forks, ND 58202, USA \\ ${ }^{2}$ National Renewable Energy Laboratory, Golden, CO 80401, USA \\ Correspondence should be addressed to Yun Ji; yun.ji@engr.und.edu
}

Received 29 March 2013; Revised 21 June 2013; Accepted 24 June 2013

Academic Editor: Lingjie Meng

Copyright (c) 2013 Hai Wang et al. This is an open access article distributed under the Creative Commons Attribution License, which permits unrestricted use, distribution, and reproduction in any medium, provided the original work is properly cited.

\begin{abstract}
This article reviewed recent development of chemical depolymerization of lignins. There were five types of treatment discussed, including base-catalyzed, acid-catalyzed, metallic catalyzed, ionic liquids-assisted, and supercritical fluids-assisted lignin depolymerizations. The methods employed in this research were described, and the important results were marked. Generally, base-catalyzed and acid-catalyzed methods were straightforward, but the selectivity was low. The severe reaction conditions (high pressure, high temperature, and extreme $\mathrm{pH}$ ) resulted in requirement of specially designed reactors, which led to high costs of facility and handling. Ionic liquids, and supercritical fluids-assisted lignin depolymerizations had high selectivity, but the high costs of ionic liquids recycling and supercritical fluid facility limited their applications on commercial scale biomass treatment. Metallic catalyzed depolymerization had great advantages because of its high selectivity to certain monomeric compounds and much milder reaction condition than base-catalyzed or acid-catalyzed depolymerizations. It would be a great contribution to lignin conversion if appropriate catalysts were synthesized.
\end{abstract}

\section{Introduction}

Lignin is a natural resource which exists in woody materials, agricultural residues, and other plant materials (so-called lignocellulosic materials). Lignocellulosic materials consist of $10-30 \%$ lignin by weight and $40 \%$ by energy [1]. However, it has mainly been used as an energy source in combustion processes, and less than 5\% lignin has been used for other purposes nowadays [2]. Because of its high energy content and polymer structure, lignin is considered as a potential renewable resource of chemicals and fuels especially in condition of escalating petroleum price and renewable energy demand. Lignin depolymerization is very promising process which can generate value added products from lignin raw materials. The primary purpose of lignin depolymerization is to convert the complex lignin compound into small molecules for fuels and basic chemicals or oligomers for further application. Considerable amount of research has been done to convert lignin into renewable fuels and chemicals using pyrolysis and gasification methods [3-8]. Pyrolysis refers to the thermal treatment of the biomass or lignin in the absence of oxygen, with or without any catalyst usually at the temperature between 300 and $600^{\circ} \mathrm{C}$ [3]. The cleavage of $\mathrm{OH}$ functional group linked to aliphatic side chain, the breaking of alkyl side chain, aryl ether, and linkage between aromatic rings occur when temperature increases, forming a mixture of phenol, guaiacol, syringol, and catechols. Moreover, the aromatic ring cracking occurs at the temperature above $500^{\circ} \mathrm{C}$ [9]. However, the process is highly complex and is affected by several factors, including feedstock type, heating rate, and reaction temperature [10]. Gasification represents a process that converts lignocellulosic materials into $\mathrm{CO}_{2}, \mathrm{CO}$, and $\mathrm{H}_{2}$ at the temperature between 700 and $1000^{\circ} \mathrm{C}$. The mixtures of the gases are referred to as "syngas", which is the only useful product from the process [3]. Biochemical method, such as fungi depolymerization of lignin, was also employed, but it took several weeks for fungi to grow, which made the process have very low efficiency $[11,12]$. Compared to pyrolysis and biochemical depolymerization, chemical treatment of lignin has its advantages on both reaction control and high selectivity, which provides great potential in lignin conversion for renewable fuels and chemicals production. 


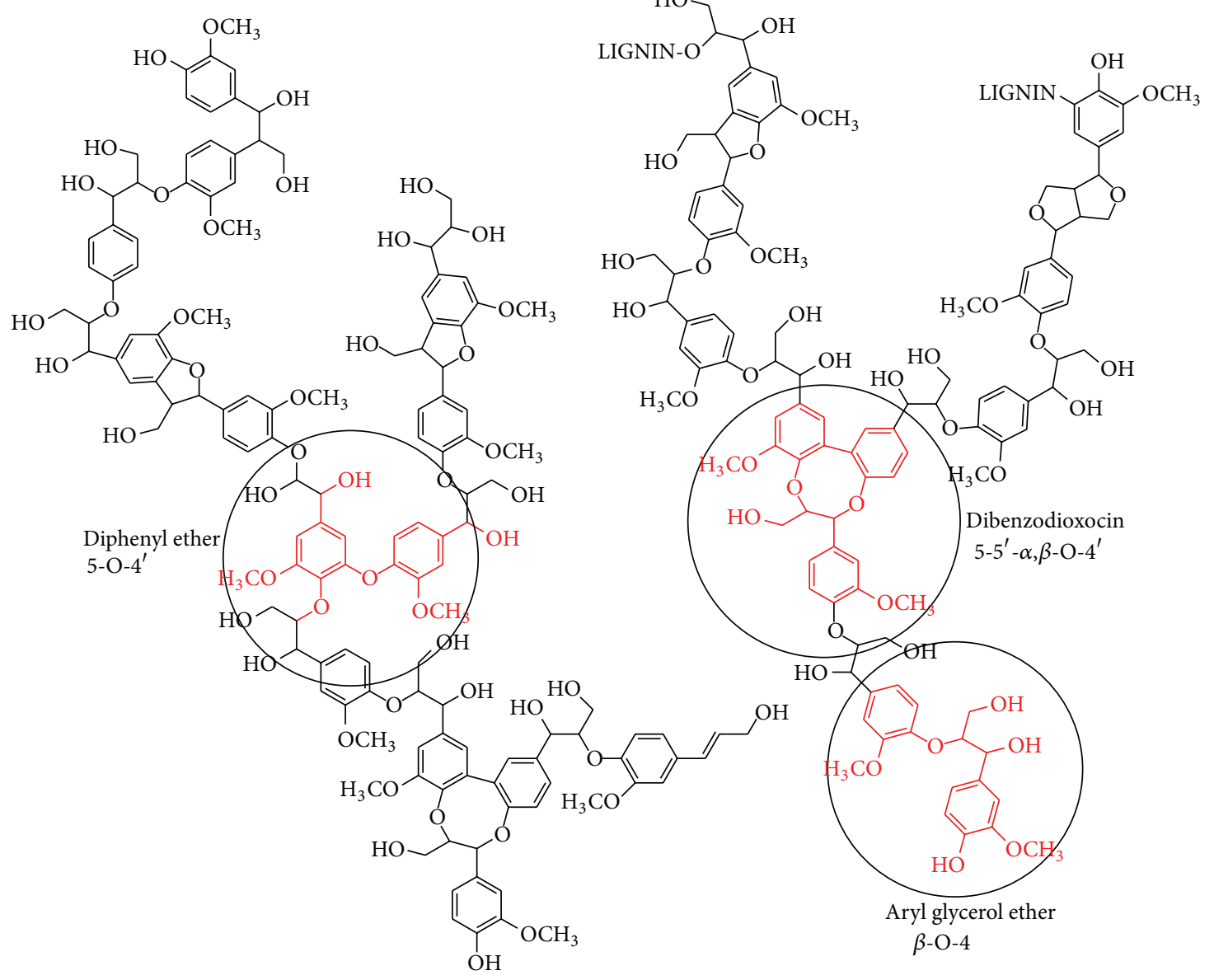

FIGURE 1: Common chemical structure of lignin [15].

Lignin can be categorized to softwood and hardwood lignins according to their raw biomass sources. Depending on the fractionation methods, lignin can also be categorized to steam explosion, kraft, organosolv, alkaline oxidation, pyrolysis lignins, and so forth [13]. The commonly recognized chemical structure of lignin is exhibited in Figure 1. Ether bond was the target for chemical attacking during chemical conversion processes. Generally, softwood has 45-48 wt.\% and hardwood has $60 \mathrm{wt} . \%$ of $\beta-\mathrm{O}-4$ aryl glycerol ether bonds. Softwood has about 5 wt.\% and hardwood has $0-$ 2 wt. $\%$ of dibenzodioxocin $5-5^{\prime}-\alpha, \beta-\mathrm{O}-4^{\prime}$ bonds. In addition, softwood has $3.5-8 \mathrm{wt} . \%$ and hardwood has $6-9 \mathrm{wt} . \%$ of diphenyl ether $5-\mathrm{O}-4^{\prime}$ linkages $[13,14]$. The differences of these linkages have effects on the depolymerization products from these biomass materials. Moreover, the amounts of some C-C linkages are also varying, such as 5-5 linkage (softwood 19-22 wt.\%, hardwood 3-9wt.\%) [14]. All the chemical patterns of ether bonds were marked in circle in Figure 1. Therefore, the reactions of ether cleavage, including $\alpha$-aryl ether and $\beta$-aryl ether, were mainly investigated. Various chemicals were selected with the purpose of breaking the mentioned chemical bonds by which lignin could be depolymerized. Generally, there are five categories of the chemical depolymerization of lignin according to different chemicals applied in the depolymerization process, which includes (1) base-catalyzed, (2) acid-catalyzed, (3) metallic catalyzed, (4) ionic liquids-assisted, and (5) supercritical fluids-assisted lignin depolymerizations.

\section{Lignin Depolymerization by Using Different Chemicals}

2.1. Base-Catalyzed Lignin Depolymerization. The treatment of lignin using sodium hydroxide aqueous solution at high temperature was straightforward process, from which phenols and phenol derivatives were obtained. Lavoie et al. used softwood and hemp lignin pretreated by steam explosion with $5 \mathrm{wt} . \%$ of $\mathrm{NaOH}$ aq at the temperature between 300 and $330^{\circ} \mathrm{C}$ under the pressure ranging from 9 to $13 \mathrm{MPa}$ [16]. There were 26 compounds identified by GC-MS after the reaction, in which guaiacol, catechol, and vanillin were more abundant. Different contents of guaiacol, catechol, and vanillin were obtained mainly because of the different ether linkages proportions in the softwood and hemp lignin. Similar base-catalyzed treatment was carried out for commercial organosolv lignin at $300^{\circ} \mathrm{C}$ and $25 \mathrm{MPa}$ by Roberts et al. [17]. Syringol, hydroxyacetophenone, and 
TABLE 1: Base-calalyzed lignin depolymerization.

\begin{tabular}{|c|c|c|c|c|c|c|}
\hline \multirow{2}{*}{ Lignin } & \multirow{2}{*}{$\begin{array}{l}\text { Base catalyst aqueous } \\
\text { solution }\end{array}$} & \multicolumn{2}{|c|}{ Reaction conditions } & \multirow{2}{*}{ Major products } & \multirow{2}{*}{$\begin{array}{l}\text { Yield } \\
\text { wt.\% }\end{array}$} & \multirow{2}{*}{ Reference } \\
\hline & & $T\left({ }^{\circ} \mathrm{C}\right)$ & $P(\mathrm{MPa})$ & & & \\
\hline \multirow{3}{*}{$\begin{array}{l}\text { Steam explosion } \\
\text { hemp lignin }\end{array}$} & \multirow{3}{*}{5 wt. $\% \mathrm{NaOH}$} & \multirow{3}{*}{$300-330$} & \multirow{3}{*}{3.5} & Guaiacol & $0.9-2.8$ & \multirow{3}{*}[16]{} \\
\hline & & & & Catechol & $0.8-3.0$ & \\
\hline & & & & Vanillin & $0.5-0.8$ & \\
\hline \multirow{3}{*}{$\begin{array}{l}\text { Steam explosion } \\
\text { softwood lignin }\end{array}$} & \multirow{3}{*}{5 wt. $\% \mathrm{NaOH}$} & \multirow{3}{*}{$300-330$} & \multirow{3}{*}{3.5} & Guaiacol & $1.2-2.1$ & \multirow{3}{*}[16]{} \\
\hline & & & & Catechol & $0.1-3.2$ & \\
\hline & & & & Vanillin & $0.3-0.5$ & \\
\hline \multirow{3}{*}{ Organosolv lignin } & \multirow{3}{*}{2 wt. $\% \mathrm{NaOH}$} & \multirow{3}{*}{300} & \multirow{3}{*}{25} & Syringol & 4.1 & \multirow{3}{*}[17]{} \\
\hline & & & & Hydroxyacetophenone & 1.6 & \\
\hline & & & & Guaiacol & 1.1 & \\
\hline Kraft lignin & 5 wt. $\% \mathrm{NaOH}$ & $270-315$ & 13 & Pyrocatechol & $0.5-4.9$ & {$[18]$} \\
\hline $\begin{array}{l}\text { Organosolv olive } \\
\text { tree pruning lignin }\end{array}$ & $\begin{array}{l}4 \text { wt.\% } \mathrm{NaOH}, \mathrm{KOH}, \\
\mathrm{Ca}(\mathrm{OH})_{2}, \mathrm{LiOH} \text {, or } \\
\mathrm{K}_{2} \mathrm{CO}_{3}\end{array}$ & 300 & 90 & Catechol & $0.1-2.4$ & {$[19]$} \\
\hline
\end{tabular}

catechol were the major products, but this research found the yield of phenols was increased by adding boric acid in the following treatment of base-catalyzed products. Similar treatment was carried out by Beauchet for treatment of kraft lignin [18]. By optimizing the reaction temperature and time, it was found that pyrocatechol was the most abundant product at $315^{\circ} \mathrm{C}$ with selectivity up to $25.8 \%$. Toledano et al. provided a different way of base-catalyzed organosolvprocessed olive tree pruning lignin depolymerization by using various bases, including $\mathrm{KOH}, \mathrm{NaOH}, \mathrm{Ca}(\mathrm{OH})_{2}$, $\mathrm{LiOH}$, and $\mathrm{K}_{2} \mathrm{CO}_{3}$, in aqueous solution instead of alcohols [19]. Catechol was the most abundant components identified after the lignin was treated by different bases.

In general, base-catalyzed lignin depolymerizations were carried out at temperature above $300^{\circ} \mathrm{C}$ and a high pressure, from which catechol, syringol, and derivatives were identified to be the most abundant components. The mechanism was the cleavage of the aryl-alkyl bond, which occurred above $270^{\circ} \mathrm{C}$. The most abundant aryl-alkyl bond was $\beta-\mathrm{O}-4$ bond, especially in lignin. Sodium cation helped to form the cation adducts, which catalyzed the formation of six-membered transition on $\beta-\mathrm{O}-4$ bond during the reaction [17]. Therefore, the concentration of base or the concentration ratio of lignin to base played a very important role in the process. Although base-catalyzed process was simple, it needed to be carried out at high temperature, and the selectivity was still difficult to control. The experiment details of cited literatures are summarized in Table 1.

2.2. Acid-Catalyzed Lignin Depolymerization. The application of acid treatment of lignin could be traced back to 1940s. Hewson and Hibbert did a series treatment of maple wood meal using different combination of acids and alcohols, including $\mathrm{HCl} /$ ethanol and formic acid/ethylene glycol, with the purpose of separating the lignin into water-soluble and water-insoluble components [40]. A relatively low temperature range of 78 to $200^{\circ} \mathrm{C}$ used in this research was not high enough to break the complex lignin structure into monomeric compounds for further usage.

Recently, acid-catalyzed method was investigated at a higher temperature range in order to depolymerize lignin [20, 21]. $10 \mathrm{wt} . \%$ of formic acid associated with $77 \mathrm{wt} \%$ of ethanol was employed in the reaction with wheat straw lignin by Gasson et al. [20]. A different proportion of formic acid and ethanol solution, which contained $10 \mathrm{wt} . \%$ of formic acid and 81 wt.\% of ethanol, was used in the reaction with wheat straw lignin but in a CSTR by Forchheim et al. [21]. Methoxyphenol, catechol, and phenol were the major components when the reaction temperature was raised from 360 to $400^{\circ} \mathrm{C}$. The maximum yields occurred at reaction time below 200 minutes. Other attempts were carried out using acid/ethanol solution system but associated with metallic catalyst enhancers [23, 24]. These researches were summarized in the section of metallic catalyzed lignin depolymerization.

The acid-catalyzed depolymerization also focused on the cleavage of $\beta-\mathrm{O}-4$ bond of the lignin, and the reaction was completed in the first 2 to 4 hours of the reaction. Formic acid or other acids provided hydrogen sources in the hydrolysis with the purpose of forming $\mathrm{H}_{3} \mathrm{O}^{+}$on the $\beta-\mathrm{O}-4$ bond or the cationic aromatic rings. The function of co-catalysts was usually to increase the selectivity. According to the experiments carried out, palladium or platinum did not decrease the activation energy of the depolymerization. In general, acid-catalyzed depolymerization required a harsh reaction condition, which could increase the cost of reaction facility and posthandling. The experiment details of acid-catalyzed lignin depolymerization are summarized in Table 2.

2.3. Metallic Catalyzed Lignin Depolymerization. Metallic catalysts were studied to increase the selectivity of lignin depolymerization. It was reported that the treatment of alcellderived lignin was carried out in presence of $\mathrm{NiCl}_{2}$ or $\mathrm{FeCl}_{3}$ by Hepditch and Thring [41]. But only $2.5 \mathrm{wt} . \%$ yield of catechol was obtained at $305^{\circ} \mathrm{C}$. More recently, several other 
TABLE 2: Acid-catalyzed lignin depolymerization.

\begin{tabular}{|c|c|c|c|c|c|c|}
\hline \multirow{2}{*}{ Lignin } & \multirow{2}{*}{$\begin{array}{l}\text { Acid catalyst } \\
\text { alcohol/aqueous solution }\end{array}$} & \multicolumn{2}{|c|}{ Reaction conditions } & \multirow{2}{*}{ Major products } & \multirow{2}{*}{$\begin{array}{l}\text { Yield } \\
\text { wt. } \%\end{array}$} & \multirow{2}{*}{ Reference } \\
\hline & & $T\left({ }^{\circ} \mathrm{C}\right)$ & $P(\mathrm{MPa})$ & & & \\
\hline \multirow{3}{*}{ Wheat straw lignin } & $10 \mathrm{wt} . \%$ formic acid & \multirow{3}{*}{360} & \multirow{3}{*}{25} & Methoxyphenols & 1.3 & \multirow{3}{*}[20]{} \\
\hline & \multirow{2}{*}{77 wt.\% ethanol } & & & Catechols & 0.5 & \\
\hline & & & & Phenols & 0.3 & \\
\hline \multirow{3}{*}{ Wheat straw lignin } & $10 \mathrm{wt} . \%$ formic acid & \multirow{3}{*}{380} & \multirow{3}{*}{25} & Methoxyphenols & 2.0 & \multirow{3}{*}[21]{} \\
\hline & \multirow{2}{*}{77 wt.\% ethanol } & & & Catechols & 1.7 & \\
\hline & & & & Phenols & 1.5 & \\
\hline \multirow{3}{*}{ Wheat straw lignin } & $10 \mathrm{wt} . \%$ formic acid & \multirow{3}{*}{380} & \multirow{3}{*}{25} & Methoxyphenols & 2.9 & \multirow{3}{*}[21]{} \\
\hline & \multirow{2}{*}{81 wt.\% ethanol } & & & Catechols & 1.5 & \\
\hline & & & & Phenols & 2.0 & \\
\hline
\end{tabular}

attempts showed higher efficiency and selectivity [22-29]. A two-step treatment process was carried out by Yoshikawa et al. in the treatment of kraft lignin [22]. Kraft lignin was treated by $\mathrm{Si}-\mathrm{Al}$ catalyst in $\mathrm{H}_{2} \mathrm{O}$ /butanol medium first, followed by reaction on $\mathrm{ZrO}_{2}-\mathrm{Al}_{2} \mathrm{O}_{3}-\mathrm{FeO}_{x}$ catalyst to increase the total recovery of phenols. The phenols yield was 6.5 to $8.6 \%$, and the conversion of lignin to methoxyphenols was 92-94\%. In order to increase the yield of low-molecular weight fraction, $20 \mathrm{wt}$.\% of Pt/C catalyst was used with formic acid and ethanol by $\mathrm{Xu}$ et al. in the treatment of organosolv switchgrass lignin [23]. An obvious increase of the guaiacol derivatives yield was observed in presence of metallic enhancer. Another attempt of optimizing the formic acidcatalyzed system was carried out by Liguori and Barth [24]. Pd catalyst and Nafion SAC-13 were used in treatment of both lignin mode compounds and spruce dry lignin pretreated by different methods in water medium at $300^{\circ} \mathrm{C}$. Guaiacol, pyrocatechol, and resorcinol were isolated, but the yields were all lower than 5 wt.\%. The slight difference of the yield of guaiacol, pyrocatechol, and resorcinol is probably because of the different lignin pretreatment methods. Although depolymerization at lower temperature was carried out in presence of $\mathrm{Pt}$ and Pd metallic enhancers compared to simple acid-catalyzed depolymerization mentioned in Section 2.2, no activation energy decrease has been reported. Future research needs to be conducted to clarify the mechanism and function of metallic enhancer in acid-catalyzed lignin depolymerization.

Base- or acid-catalyzed cracking was usually performed at very high temperature (above $300^{\circ} \mathrm{C}$ ) [16-21, 23, 24]. However, efforts were made to decrease the reaction activation energy in order to carry out the lignin depolymerization under mild condition (below $250^{\circ} \mathrm{C}$ ). Research from Song et al. exhibited a method of nickel compound catalyzed depolymerization of lignosulfonate into guaiacols [25]. The nickel catalyst provided a high conversion of above $60 \%$ and a high selectivity of 75 to $95 \%$ to guaiacols. More importantly, the reaction temperature was decreased to $200^{\circ} \mathrm{C}$ from around $380^{\circ} \mathrm{C}$ compared with the pyrolysis process only in presence of acid or base as mentioned in Section 2.2. Another attempt from Song et al. on the treatment of birch wood lignin by nickel catalyst showed a selectivity of above $90 \%$ to propanyguaicol and propenylsyringol and a conversion of more than 50\% [26]. Ye et al. reported their work on mild hydrolysis of enzymatic hydrolysis corn stalk lignin between 200 and $250^{\circ} \mathrm{C}$ [27]. In the presence of $\mathrm{Ru} / \mathrm{C}$, $\mathrm{Pt} / \mathrm{C}$, or $\mathrm{Pd} / \mathrm{C}$ catalysts, the maximum yields are $3.1 \%$ of 4-ethylphenol and $1.4 \%$ of 4-ethylguaiacol. Toledano et al. used metal nanoparticles including nickel, palladium, platinum, and ruthenium supported by mesoporous AlSBA-15 with the assistance of microwave in the treatment of lignin separated from organosolv olive tree pruning lignin [28]. The results showed that the most abundant product was diethyl phthalate in presence of $\mathrm{Ni}$ or Pd catalyst and tetralin solvent. Although the yield was $1.1 \mathrm{wt} . \%$, the reaction temperature was only $140^{\circ} \mathrm{C}$, which was lower than 200 to $300^{\circ} \mathrm{C}$ in other published research. K10 montmorillonite clay $\left(\mathrm{Al}_{2} \mathrm{O}_{3}-4 \mathrm{SiO}_{2}-x \mathrm{H}_{2} \mathrm{O}\right)$ was applied in the treatment of guaiacyl dehydrogenation oligomers at only $100^{\circ} \mathrm{C}$, which led to a degradation of $35 \mathrm{wt}$ \% of the model compounds [29].

By introducing metallic catalysts, the activation energy of the depolymerization was decreased to great extent, which resulted in mild reaction condition. Metallic catalyzing still targeted the $\mathrm{C}-\mathrm{O}$ and $\mathrm{C}-\mathrm{C}$ cleavages of the lignin in presence of hydrogen sources like ethanol or water. Nickel or other solid catalysts provided accessible metal sites in the external surface, where the chemical reaction took place in the depolymerization process. This kind of method not only increased the selectivity but decreased the required reaction temperature, which showed great potential. The experiment details of metallic catalyzed lignin depolymerization are summarized in Table 3.

The deactivation issue in metallic catalysts is well known in the biomass pyrolysis. Some of the research to which this article referred mentioned their concern on this point [2527]. For example, the work done by Song et al. on lignosulfonate depolymerization by using nickel heterogeneous catalyst mentioned that the nickel catalysts helped generate active $\mathrm{H}$ species. These active $\mathrm{H}$ species combined with nickel sulfides to form $\mathrm{H}_{2} \mathrm{~S}$ and regenerated $\mathrm{Ni}(0)$ site for next catalyzing cycle. This mechanism made the nickel heterogeneous catalysts recyclable [25]. Another research from Song et al. also mentioned that the $\mathrm{Ni} / \mathrm{C}$ catalysts were recycled 4 times without showing obvious deactivation in birch wood lignin depolymerization [26]. In the work of 
TABLE 3: Metallic catalyzed lignin depolymerization.

\begin{tabular}{|c|c|c|c|c|c|c|}
\hline \multirow{2}{*}{ Lignin } & \multirow{2}{*}{ Catalyst } & \multicolumn{2}{|c|}{ Reaction conditions } & \multirow{2}{*}{ Major products } & \multirow{2}{*}{ Yield } & \multirow{2}{*}{ Reference } \\
\hline & & $T\left({ }^{\circ} \mathrm{C}\right)$ & $P(\mathrm{MPa})$ & & & \\
\hline \multirow[t]{2}{*}{ Kraft lignin } & $\begin{array}{l}\text { (1) } \mathrm{Si}-\mathrm{Al} \\
\text { catalyst/ } \mathrm{H}_{2} \mathrm{O} / \text { butanol }\end{array}$ & $200-350$ & $1.1-23$ & Phenols & 6.5 & {$[22]$} \\
\hline & (2) $\mathrm{ZrO}_{2}-\mathrm{Al}_{2} \mathrm{O}_{3}-\mathrm{FeO}_{x}$ & 300 & & & & \\
\hline \multirow{3}{*}{$\begin{array}{l}\text { Organosolv switchgrass } \\
\text { lignin }\end{array}$} & 16 wt. $\%$ formic acid & \multirow{3}{*}{350} & & 4-Propylguaiacol & 7.8 & \multirow{3}{*}[23]{} \\
\hline & 4 wt. $\% \mathrm{Pt} / \mathrm{C}$ & & & 4-Metbylouniacol & 50 & \\
\hline & 80 wt.\% ethanol & & & 4-ivetnyıgualacor & 5.0 & \\
\hline \multirow{3}{*}{$\begin{array}{l}\text { Acidic hydrolysis spruce } \\
\text { lignin }\end{array}$} & $4.4 \mathrm{wt} . \%$ formic acid & \multirow{3}{*}{300} & \multirow{3}{*}{9.6} & Guaiacol & 2.0 & \multirow{3}{*}[24]{} \\
\hline & 0.15 wt. $\%$ Pd catalyst & & & Pyrocatechol & 1.8 & \\
\hline & $\begin{array}{l}0.94 \text { wt.\% Nafion } \\
\text { SAC-13 }\end{array}$ & & & Resorcinol & 0.5 & \\
\hline \multirow{3}{*}{$\begin{array}{l}\text { Enzymatic hydrolysis spruce } \\
\text { lignin }\end{array}$} & $4.4 \mathrm{wt} . \%$ formic acid & \multirow{3}{*}{300} & \multirow{3}{*}{9.6} & Guaiacol & 1.7 & \multirow{3}{*}[24]{} \\
\hline & 0.15 Pd catalyst & & & Pyrocatechol & 1.3 & \\
\hline & $\begin{array}{l}0.94 \text { wt.\% Nafion } \\
\text { SAC-13 }\end{array}$ & & & Resorcinol & 1.0 & \\
\hline \multirow{3}{*}{ Kraft spruce lignin } & $4.4 \mathrm{wt} . \%$ formic acid & \multirow{3}{*}{300} & \multirow{3}{*}{9.6} & Guaiacol & 4.7 & \multirow{3}{*}[24]{} \\
\hline & 0.15 wt. $\%$ Pd catalyst & & & Pyrocatechol & 4.9 & \\
\hline & $\begin{array}{l}0.94 \text { wt.\% Nafion } \\
\text { SAC-13 }\end{array}$ & & & Resorcinol & 1.2 & \\
\hline Lignosulfonate & $\begin{array}{l}\mathrm{Ni} / \mathrm{C}, \mathrm{NiLa} / \mathrm{C}, \\
\mathrm{NiPt} / \mathrm{C}, \mathrm{NiCu} / \mathrm{C}, \\
\mathrm{NiPd} / \mathrm{C} \text {, and } \mathrm{NiCe} / \mathrm{C}\end{array}$ & 200 & 5 & Guaiacol & 10 & {$[25]$} \\
\hline \multirow{2}{*}{ Birch sawdust lignin } & \multirow{2}{*}{$\mathrm{Ni} / \mathrm{C}$} & \multirow{2}{*}{200} & & Propenylguaiacol & 12 & \multirow{2}{*}[26]{} \\
\hline & & & & Propenylsyringol & 36 & \\
\hline \multirow{2}{*}{$\begin{array}{l}\text { Enzymatic hydrolysis corn } \\
\text { stalk lignin }\end{array}$} & \multirow{2}{*}{$\mathrm{Pt} / \mathrm{C}, \mathrm{Pd} / \mathrm{C}, \mathrm{Ru} / \mathrm{C}$} & \multirow{2}{*}{$200-250$} & \multirow{2}{*}{$1-6$} & 4-Ethylphenol & $0.13-3.1$ & \multirow{2}{*}[27]{} \\
\hline & & & & 4-Ethylguaicol & $0.06-1.4$ & \\
\hline $\begin{array}{l}\text { Organosolv olive tree } \\
\text { pruning lignin }\end{array}$ & $\begin{array}{l}\mathrm{Ni}, \mathrm{Pd}, \mathrm{Pt} \text {, or } \mathrm{Ru} \\
\text { supported by } \\
\text { mesoporous } \\
\text { Al-SBA-15 }\end{array}$ & 140 & & Diethyl phthalate & 1.1 & {$[28]$} \\
\hline $\begin{array}{l}\text { Guaiacyl dehydrogenation } \\
\text { oligomers }\end{array}$ & $\begin{array}{l}\text { K10 montmorillonite } \\
\text { clay }\left(\mathrm{Al}_{2} \mathrm{O}_{3}-4 \mathrm{SiO}_{2}-\right. \\
\left.x \mathrm{H}_{2} \mathrm{O}\right) / \mathrm{HCl}\end{array}$ & 100 & & Low-molecular weight products & - & {$[29]$} \\
\hline
\end{tabular}

Ye et al., the $\mathrm{Ru} / \mathrm{C}$ catalyst was also recycled and showed very good activity [27]. The other research cited in this section did not mention the recycle of catalysts, which made it necessary to study the deactivation of metallic catalysts in the future.

2.4. Ionic Liquids-Assisted Lignin Depolymerization. Ionic liquid was found to be used in separation of lignin and cellulose from raw lignocellulosic materials. Ionic liquids, includzing 1-butyl-3-methylimidazolium acesulfamate ([BMIM][Ace]) and 1-ethyl-3-methylimidazolium acesulfamate ([EMIM][Ace]), were applied in the treatment of wood powder of Pinus radiata lignin by Pinkert et al. [42]. To break the $\beta$-O- 4 bond under the mild conditions (below $250^{\circ} \mathrm{C}$ ), ionic liquid was also employed in the depolymerization of lignin. The depolymerization of organosolv beech lignin in presence of 1-ethyl-3-methylimidazolium-trifluoromethansulfonate ([EMIM] $\left.\left[\mathrm{CF}_{3} \mathrm{SO}_{3}\right]\right)$ associated with $\mathrm{Mn}\left(\mathrm{NO}_{3}\right)_{2}$ was carried out at $100^{\circ} \mathrm{C}$ and $8.4 \mathrm{MPa}$ by Stärk et al. [30]. The most important point drawn from their research was that 2,6-dimethoxy-1,4-benzoquinone (DMBQ) was separated as a pure substance in $11.5 \%$ overall yield as the final product. Another attempt of $[\mathrm{EMIM}]\left[\mathrm{CF}_{3} \mathrm{SO}_{3}\right]$ associated with Brønsted acid was carried out by Binder et al. in depolymerization of lignin model compound [31]. The reaction was carried out at $200^{\circ} \mathrm{C}$, and $11.6 \mathrm{~mol} \%$ or $7.9 \mathrm{wt} . \%$ of guaiacol was obtained from 2-methoxy-4-(2-propenyl)phenol and cleaved 2-phenylethyl phenyl ether, a model for lignin ethers. For both the lignin and the model compounds, ionic liquid associated with ionic salt exhibited high selectivity. Acidic ionic liquid 1-H-3-methylimidazolium chloride [HMIM] [Cl] was used in the depolymerization of oak wood lignin at 110 to $150^{\circ} \mathrm{C}$ by Cox and Ekerdt [32]. The alkyl-aryl ether linkage cleavages were observed in the research. A series of work were done by Jia et al. with the purpose of degrading lignin in various ionic liquids [33-35]. 1-H-3-methylimidazolium chloride was used in depolymerization of both guaiacylglycerol- $\beta$ guaiacyl ether and veratrylglycerol- $\beta$-guaiacyl ether model compounds to produce guaiacol with the yield of $70 \%$ at 
TABLE 4: Ionic liquids-assisted lignin depolymerization.

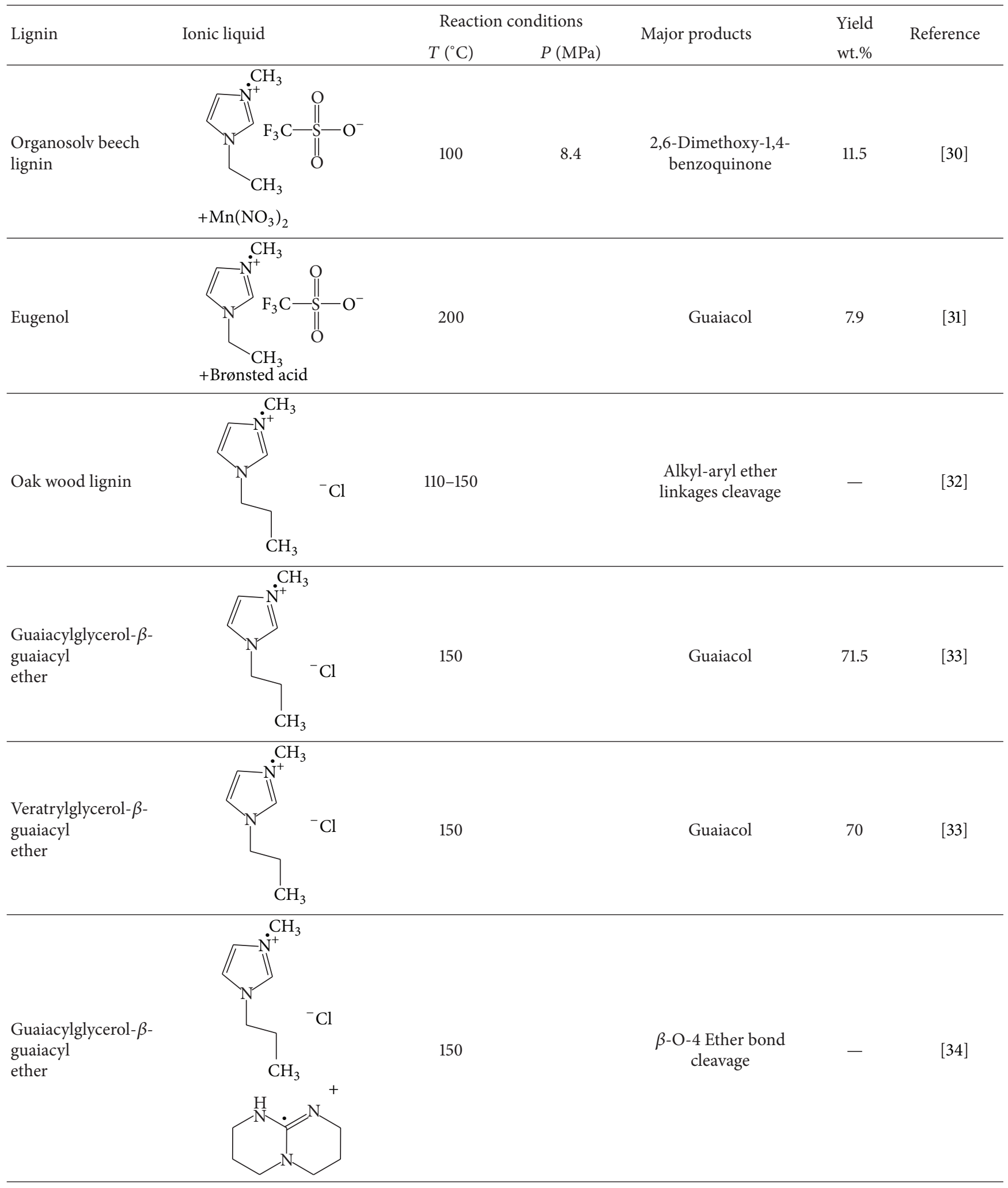


TABLE 4: Continued.

\begin{tabular}{|c|c|c|c|c|c|c|}
\hline \multirow{2}{*}{ Lignin } & \multirow{2}{*}{ Ionic liquid } & \multicolumn{2}{|c|}{ Reaction conditions } & \multirow{2}{*}{ Major products } & \multirow{2}{*}{$\begin{array}{l}\text { Yield } \\
\text { wt.\% }\end{array}$} & \multirow{2}{*}{ Reference } \\
\hline & & $T\left({ }^{\circ} \mathrm{C}\right)$ & $P(\mathrm{MPa})$ & & & \\
\hline $\begin{array}{l}\text { Guaiacylglycerol- } \beta \text { - } \\
\text { guaiacyl } \\
\text { ether }\end{array}$ & ${\stackrel{-\mathrm{N}^{+}}{\mathrm{CH}_{3}}}^{\mathrm{CH}_{3} \mathrm{C}}$ & 150 & & Guaiacol & 75 & {$[35]$} \\
\hline
\end{tabular}

TABLE 5: Supercritical fluids-assisted lignin depolymerization.

\begin{tabular}{|c|c|c|c|c|c|c|}
\hline \multirow{2}{*}{ Lignin } & \multirow{2}{*}{ Supercritical fluid } & \multicolumn{2}{|c|}{ Reaction condition } & \multirow{2}{*}{ Major products } & \multirow{2}{*}{$\begin{array}{l}\text { Yield } \\
\text { wt. } \%\end{array}$} & \multirow{2}{*}{ Reference } \\
\hline & & $T\left({ }^{\circ} \mathrm{C}\right)$ & $P(\mathrm{MPa})$ & & & \\
\hline \multirow{2}{*}{ Kraft lignins } & Methanol/KOH & \multirow{2}{*}{290} & & Catechol & \multirow{2}{*}{-} & \multirow{2}{*}[36]{} \\
\hline & Ethanol/KOH & & & Phenol & & \\
\hline \multirow{2}{*}{ Organosolv lignin } & Methanol/KOH & \multirow{2}{*}{290} & & Catechol & \multirow{2}{*}{-} & \multirow{2}{*}[36]{} \\
\hline & Ethanol/KOH & & & Phenol & & \\
\hline \multirow{3}{*}{ Alkaline lignin } & \multirow{3}{*}{ Water } & \multirow{3}{*}{300} & \multirow{3}{*}{25} & Catechol & 28.37 & \multirow{3}{*}[37]{} \\
\hline & & & & Phenol & 7.53 & \\
\hline & & & & Cresol & 11.67 & \\
\hline Organosolv lignin & Water $+p$-cresol & $350-420$ & & 2-(Hydroxy-benzyl)-4-methyl-phenol & $<75$ & {$[38]$} \\
\hline \multirow{3}{*}{$\begin{array}{l}\text { Organosolv } \\
\text { hardwood lignin }\end{array}$} & \multirow{3}{*}{$\mathrm{CO}_{2} /$ acetone/water } & \multirow{3}{*}{$300-370$} & \multirow{3}{*}{10} & Syringol & 3.6 & \multirow{3}{*}[39]{} \\
\hline & & & & Guaiacol & 1.6 & \\
\hline & & & & 2-Methyoxy-4-methyl-phenol & 1.6 & \\
\hline \multirow{2}{*}{$\begin{array}{l}\text { Organosolv wheat } \\
\text { straw lignin }\end{array}$} & \multirow{2}{*}{$\mathrm{CO}_{2} /$ acetone/water } & \multirow{2}{*}{$300-370$} & \multirow{2}{*}{10} & Syringic acid & 2.2 & \multirow{2}{*}[39]{} \\
\hline & & & & Guaiacol & 1.6 & \\
\hline
\end{tabular}

$150^{\circ} \mathrm{C}$ [33]. 1-H-3-methylimidazolium chloride with 1,5,7triazabicyclo[4.4.0] dec-5-ene was used in depolymerization of guaiacylglycerol- $\beta$-guaiacyl ether model compounds, from which $40 \%$ cleavage of $\beta-\mathrm{O}-4$ bond was found [34]. The $75 \%$ yield of guaiacol was observed in depolymerization of guaiacylglycerol- $\beta$-guaiacyl ether model compounds in presence of 1-H-3-methylimidazolium chloride methylsulfate [35].

Currently, it has been proofed that some ionic liquids are appropriate solvents for lignin dissolution [43]. Acid associated with ionic liquid, such as Brønsted acid, was believed to be the catalyst which provided the hydrogen sources. However, the high cost of the ionic liquids limited their application on large quantity of lignin depolymerization. The recycle of ionic liquid is very necessary due to its high cost [44]. However, there is difficulty in separation of ionic liquid with lignin-derived molecules because of the $\pi$ $\pi$ interaction between ionic liquid and aromatic moieties [13]. Therefore, the use of ionic liquid in lignin depolymerization may be limited. A summary of ionic liquid-assisted lignin depolymerization is shown in Table 4.

2.5. Supercritical Fluids-Assisted Lignin Depolymerization. Supercritical fluid was selected to be the medium for lignin depolymerization. The treatment of kraft- and organosolvderived lignins using $\mathrm{KOH}$ or other bases in supercritical methanol or ethanol was reported in 1990s, indicating that the supercritical liquid had effects on lignin depolymerization [36, 45]. Recently, the use of supercritical fluid on the treatment of lignin attracted researchers' interest again. Supercritical water treatment of alkaline lignin was carried out by Wahyudiono et al. [37]. Under the condition of $300^{\circ} \mathrm{C}$ and 25-40 MPa, identified products included mainly catechol (28.37 wt.\%), phenol (7.53 wt.\%), and cresol (11.67 wt.\%). Supercritical water associated with $p$-cresol was applied as the medium in treatment of organosolv lignin at the temperature between 350 and $420^{\circ} \mathrm{C}$ by Takami et al. [38]. 2-(Hydroxybenzyl)-4-methyl-phenol (BMP) with a $75 \mathrm{wt} . \%$ yield was recovered from the reaction mixtures. Another attempt by Gosselink et al. was using $\mathrm{CO}_{2}$ /acetone/water supercritical fluid to treat organosolv hardwood and wheat straw lignins at the temperature between 300 and $370^{\circ} \mathrm{C}$ under $10 \mathrm{MPa}$, from which syringol and guaiacol were obtained [39]. The difference of the yield of some depolymerization products is mainly because of the different linkage contents between hardwood and wheat straw lignin.

Similar to ionic liquid, supercritical fluid was employed as the solvent in the depolymerization system due to its 
good solubility. Hydrogen sources for the hydrolysis were provided from acid and alcohol. Even though supercritical liquid exhibited high selectivity and convenience on products and solvent separation, the high cost still restricted its development to be a widely used method for lignin conversion. A summary of supercritical fluids-assisted lignin depolymerization is made in Table 5.

\section{Summary}

Base-catalyzed, acid-catalyzed, metallic catalyzed, ionic liquids-assisted, and supercritical fluids assisted lignin depolymerizations were summarized and compared in this article. In general, base-catalyzed and acid-catalyzed methods required high reaction temperature (above $300^{\circ} \mathrm{C}$ ) and high pressure $(10 \mathrm{MPa})$, which resulted in high costs of facility and handling. High selectivity and conversion are great advantages of ionic liquids- and supercritical fluids-assisted lignin depolymerizations. However, the high cost is the major obstacle to their wide applications. Metallic catalyzed depolymerization had great potential because of its high selectivity to some target products and less severe reaction conditions. Current research on metallic catalyzed depolymerization showed that $\mathrm{Ni}$ - and Pt-based catalysts have relatively high conversion of lignin model compounds and high selectivity to certain monomeric products. The development of new transition metal-based catalysts for lignin depolymerization will be the trend in the future as well as the performance of these catalysts on lignin rather than model compounds.

\section{Acknowledgments}

The authors acknowledge the funding from the National Renewable Energy Laboratory (NREL) in Golden, CO (Contract no. AEV-0-40634-01), North Dakota EPSCoR, and the University of North Dakota Faculty Seed Grant.

\section{References}

[1] R. D. Perlack, L. L. Wright, A. F. Turhollow, R. L. Graham, B. J. Stokes, and D. C. Erbach, "U. S. Department of Energy, Biomass as feedstock for a bioenergy and bioproducts industry: the technical feasibility of a billion-ton annual supply," 2005.

[2] M. Kleinert and T. Barth, "Phenols from lignin," Chemical Engineering and Technology, vol. 31, no. 5, pp. 736-745, 2008.

[3] G. W. Huber, S. Iborra, and A. Corma, "Synthesis of transportation fuels from biomass: chemistry, catalysts, and engineering," Chemical Reviews, vol. 106, no. 9, pp. 4044-4098, 2006.

[4] R. Zanzi, K. Sjöström, and E. Björnbom, "Rapid pyrolysis of agricultural residues at high temperature," Biomass and Bioenergy, vol. 23, no. 5, pp. 357-366, 2002.

[5] A. Demirbas, "Effects of temperature and particle size on bio-char yield from pyrolysis of agricultural residues," Journal of Analytical and Applied Pyrolysis, vol. 72, no. 2, pp. 243-248, 2004.

[6] L. Wei, S. Xu, L. Zhang et al., "Characteristics of fast pyrolysis of biomass in a free fall reactor," Fuel Processing Technology, vol. 87, no. 10, pp. 863-871, 2006.
[7] T. Hosoya, H. Kawamoto, and S. Saka, "Pyrolysis behaviors of wood and its constituent polymers at gasification temperature," Journal of Analytical and Applied Pyrolysis, vol. 78, no. 2, pp. 328-336, 2007.

[8] C. Gustafsson and T. Richards, "Pyrolysis kinetics of washed precipitated lignin," BioResources, vol. 4, no. 1, pp. 26-37, 2009.

[9] M. P. Pandey and C. S. Kim, "Lignin depolymerization and conversion: a review of thermochemical methods," Chemical Engineering and Technology, vol. 34, no. 1, pp. 29-41, 2011.

[10] D. Ferdous, A. K. Dalai, S. K. Bej, and R. W. Thring, "Pyrolysis of lignins: experimental and kinetics studies," Energy and Fuels, vol. 16, no. 6, pp. 1405-1412, 2002.

[11] S. M. Geib, T. R. Filley, P. G. Hatcher et al., "Lignin degradation in wood-feeding insects," Proceedings of the National Academy of Sciences of the United States of America, vol. 105, no. 35, pp. 12932-12937, 2008.

[12] N. S. Reading, K. D. Welch, and S. D. Aust, "Free radical reactions of wood-degrading fungi," ACS Symposium Series, vol. 845, pp. 16-31, 2003.

[13] J. Zakzeski, P. C. A. Bruijnincx, A. L. Jongerius, and B. M. Weckhuysen, "The catalytic valorization of lignin for the production of renewable chemicals," Chemical Reviews, vol. 110, no. 6, pp. 3552-3599, 2010.

[14] W. Boerjan, J. Ralph, and M. Baucher, "Lignin Biosynthesis," Annual Review of Plant Biology, vol. 54, pp. 519-546, 2003.

[15] C. Crestini, M. Crucianelli, M. Orlandi, and R. Saladino, "Oxidative strategies in lignin chemistry: a new environmental friendly approach for the functionalisation of lignin and lignocellulosic fibers," Catalysis Today, vol. 156, no. 1-2, pp. 8-22, 2010.

[16] J.-M. Lavoie, W. Baré, and M. Bilodeau, "Depolymerization of steam-treated lignin for the production of green chemicals," Bioresource Technology, vol. 102, no. 7, pp. 4917-4920, 2011.

[17] V. M. Roberts, V. Stein, T. Reiner, A. Lemonidou, X. Li, and J. A. Lercher, "Towards quantitative catalytic lignin depolymerization," Chemistry, vol. 17, no. 21, pp. 5939-5948, 2011.

[18] R. Beauchet, F. Monteil-Rivera, and J. M. Lavoie, "Conversion of lignin to aromatic-based chemicals (L-chems) and biofuels (L-fuels)," Bioresource Technology, vol. 121, pp. 328-334, 2012.

[19] A. Toledano, L. Serrano, and J. Labidi, "Organosolv lignin depolymerization with different base catalysts," Journal of Chemical Technology and Biotechnology, vol. 87, no. 11, pp. 1593-1599, 2012.

[20] J. R. Gasson, D. Forchheim, T. Sutter, U. Hornung, A. Kruse, and T. Barth, "Modeling the lignin degradation kinetics in an ethanol/formic acid solvolysis approach. Part 1. Kinetic model development," Industrial and Engineering Chemistry Research, vol. 51, no. 32, pp. 10595-10606, 2012.

[21] D. Forchheim, J. R. Gasson, U. Hornung, A. Kruse, and T. Barth, "Modeling the lignin degradation kinetics in an ethanol/formic acid solvolysis approach. Part 2. Validation and transfer to variable conditions," Industrial and Engineering Chemistry Research ., vol. 51, no. 32, pp. 15053-1 15063, 2012.

[22] T. Yoshikawa, T. Yagi, S. Shinohara et al., "Production of phenols from lignin via depolymerization and catalytic cracking," Fuel Processing Technology, vol. 108, pp. 69-75, 2012.

[23] W. Xu, S. J. Miller, P. K. Agrawal, and C. W. Jones, "Depolymerization and hydrodeoxygenation of switchgrass lignin with formic acid," ChemSusChem, vol. 5, no. 4, pp. 667-675, 2012.

[24] L. Liguori and T. Barth, "Palladium-Nafion SAC-13 catalysed depolymerisation of lignin to phenols in formic acid and water," Journal of Analytical and Applied Pyrolysis, vol. 92, no. 2, pp. 477-484, 2011. 
[25] Q. Song, F. Wang, and J. Xu, "Hydrogenolysis of lignosulfonate into phenols over heterogeneous nickel catalysts," Chemical Communications, vol. 48, no. 56, pp. 7019-77021, 2012.

[26] Q. Song, F. Wang, J. Cai et al., "Lignin depolymerization (LDP) in alcohol over nickel-based catalysts via a fragmentationhydrogenolysis process," Energy and Environmental Science, vol. 6, no. 3, pp. 994-1007, 2013.

[27] Y. Ye, Y. Zhang, J. Fan, and J. Chang, "Selective production of 4-ethylphenolics from lignin via mild hydrolysis," Bioresource Technology, vol. 118, pp. 648-651, 2012.

[28] A. Toledano, L. Serrano, A. Pineda, A. A. Romero, R. Luque, and J. Labidi, "Microwave-assisted depolymerisation of organosolv lignin via mild hydrogen-free hydrogenolysis: catalyst screening," Applied Catalysis B, 2012.

[29] F. Bouxin, S. Baumberger, B. Pollet, A. Haudrechy, J.-H. Renault, and P. Dole, "Acidolysis of a lignin model: investigation of heterogeneous catalysis using Montmorillonite clay," Bioresource Technology, vol. 101, no. 2, pp. 736-744, 2010.

[30] K. Stärk, N. Taccardi, A. Bösmann, and P. Wasserscheid, "Oxidative depolymerization of lignin in ionic liquids," ChemSusChem, vol. 3, no. 6, pp. 719-723, 2010.

[31] J. B. Binder, M. J. Gray, J. F. White, Z. C. Zhang, and J. E. Holladay, "Reactions of lignin model compounds in ionic liquids," Biomass and Bioenergy, vol. 33, no. 9, pp. 1122-1130, 2009.

[32] B. J. Cox and J. G. Ekerdt, "Depolymerization of oak wood lignin under mild conditions using the acidic ionic liquid 1H-3-methylimidazolium chloride as both solvent and catalyst," Bioresource Technology, vol. 118, pp. 584-588, 2012.

[33] S. Jia, B. J. Cox, X. Guo, Z. C. Zhang, and J. G. Ekerdt, "Decomposition of a phenolic lignin model compound over organic Nbases in an ionic liquid," Holzforschung, vol. 64, no. 5, pp. 577$580,2010$.

[34] S. Jia, B. J. Cox, X. Guo, Z. C. Zhang, and J. G. Ekerdt, “Cleaving the $\beta$-O- 4 bonds of lignin model compounds in an acidic ionic liquid, 1-H-3-methylimidazolium chloride: an optional strategy for the degradation of lignin," ChemSusChem, vol. 3, no. 9, pp. 1078-1084, 2010.

[35] S. Jia, B. J. Cox, X. Guo, Z. C. Zhang, and J. G. Ekerdt, "Catalysis of lignin depolymerization in ionic liquids," in Proceedings of the 240th ACS National Meeting and Exposition, Boston, Mass, USA, August 2010.

[36] J. E. Miller, L. Evans, A. Littlewolf, and D. E. Trudell, "Batch microreactor studies of lignin and lignin model compound depolymerization by bases in alcohol solvents," Fuel, vol. 78, no. 11, pp. 1363-1366, 1999.

[37] W. Wahyudiono, M. Sasaki, and M. Goto, "Recovery of phenolic compounds through the decomposition of lignin in near and supercritical water," Chemical Engineering and Processing, vol. 47, no. 9-10, pp. 1609-1619, 2008.

[38] S. Takami, K. Okuda, X. Man, M. Umetsu, S. Ohara, and T. Adschiri, "Kinetic study on the selective production of 2 (Hydroxybenzyl)-4-methylphenol from organosolv lignin in a mixture of supercritical water and p-cresol," Industrial and Engineering Chemistry Research, vol. 51, no. 13, pp. 4804-4808, 2012.

[39] R. J. A. Gosselink, W. Teunissen, J. E. G. van Dam et al., "Lignin depolymerisation in supercritical carbon dioxide/acetone/water fluid for the production of aromatic chemicals," Bioresource Technology, vol. 106, pp. 173-177, 2012.
[40] W. B. Hewson and H. Hibbert, "Studies on lignin and related compounds. LXV. Re-ethanolysis of isolated lignins," Journal of the American Chemical Society, vol. 65, no. 6, pp. 1173-1176, 1943.

[41] M. M. Hepditch and R. W. Thring, "Degradation of solvolysis lignin using Lewis acid catalysts," Canadian Journal of Chemical Engineering, vol. 78, no. 1, pp. 226-231, 2000.

[42] A. Pinkert, D. F. Goeke, K. N. Marsh, and S. Pang, "Extracting wood lignin without dissolving or degrading cellulose: investigations on the use of food additive-derived ionic liquids," Green Chemistry, vol. 13, no. 11, pp. 3124-3136, 2011.

[43] I. Kilpeläinen, H. Xie, A. King, M. Granstrom, S. Heikkinen, and D. S. Argyropoulos, "Dissolution of wood in ionic liquids," Journal of Agricultural and Food Chemistry, vol. 55, no. 22, pp. 9142-9148, 2007.

[44] S. Zhu, "Use of ionic liquids for the efficient utilization of lignocellulosic materials," Journal of Chemical Technology and Biotechnology, vol. 83, no. 6, pp. 777-779, 2008.

[45] E. Dorrestijn, M. Kranenburg, D. Poinsot, and P. Mulder, "Lignin depolymerization in hydrogen-donor solvents," Holzforschung, vol. 53, no. 6, pp. 611-616, 1999. 

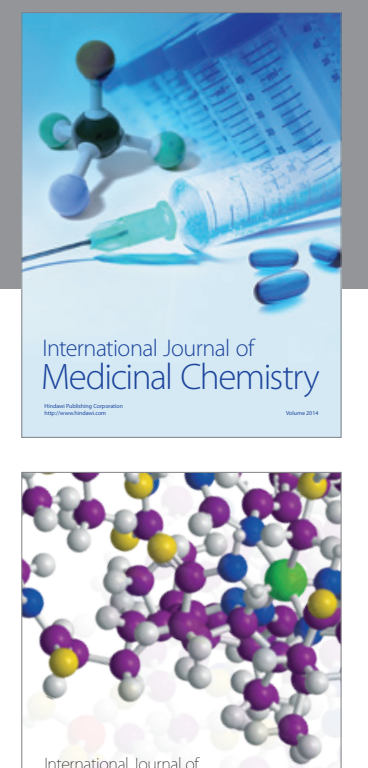

\section{Carbohydrate} Chemistry

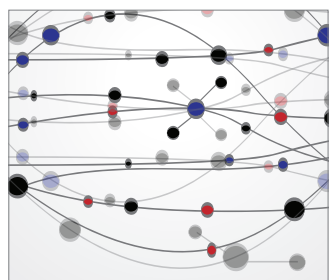

The Scientific World Journal
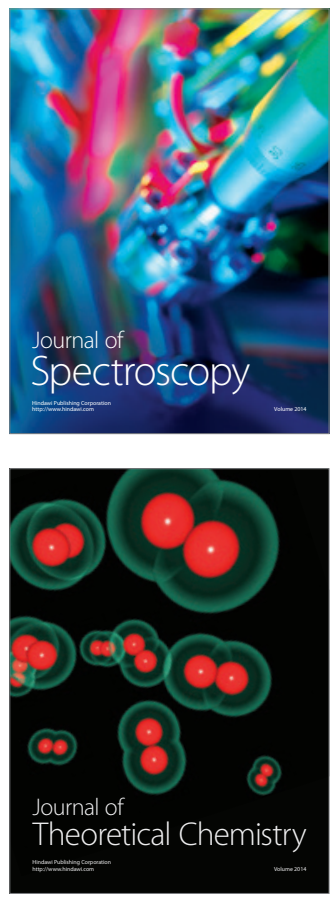
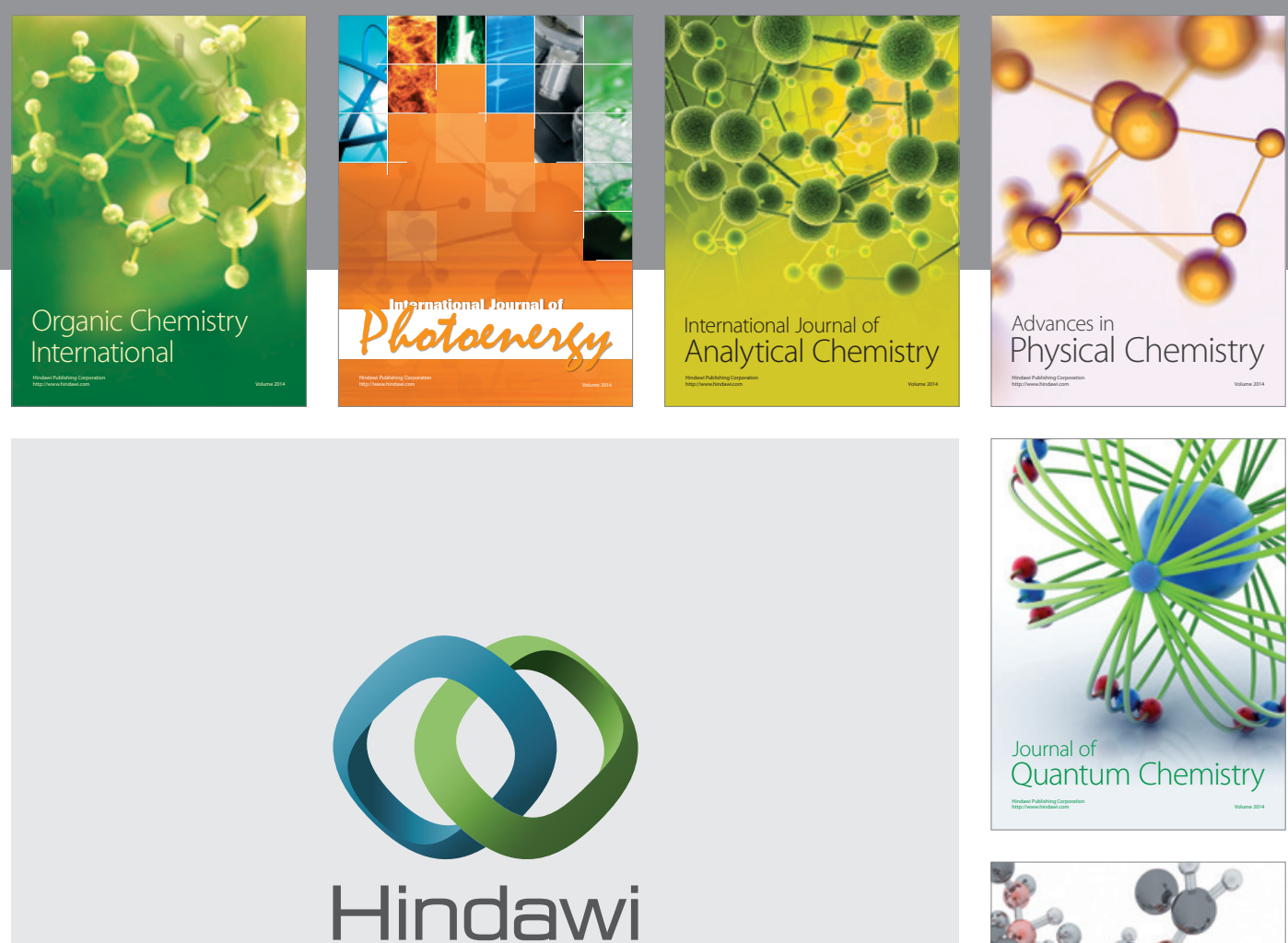

Submit your manuscripts at

http://www.hindawi.com

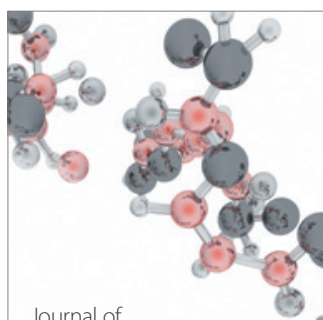

Analytical Methods

in Chemistry

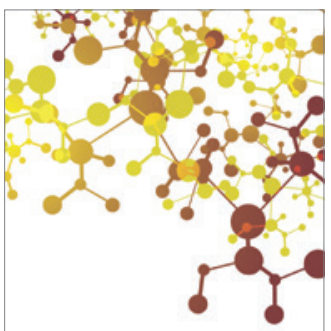

Journal of

Applied Chemistry

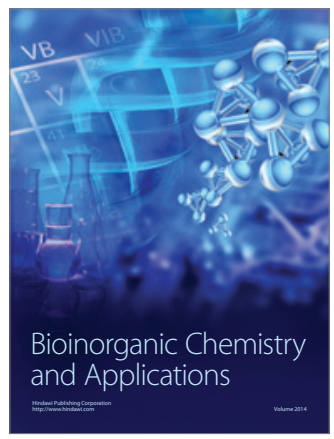

Inorganic Chemistry
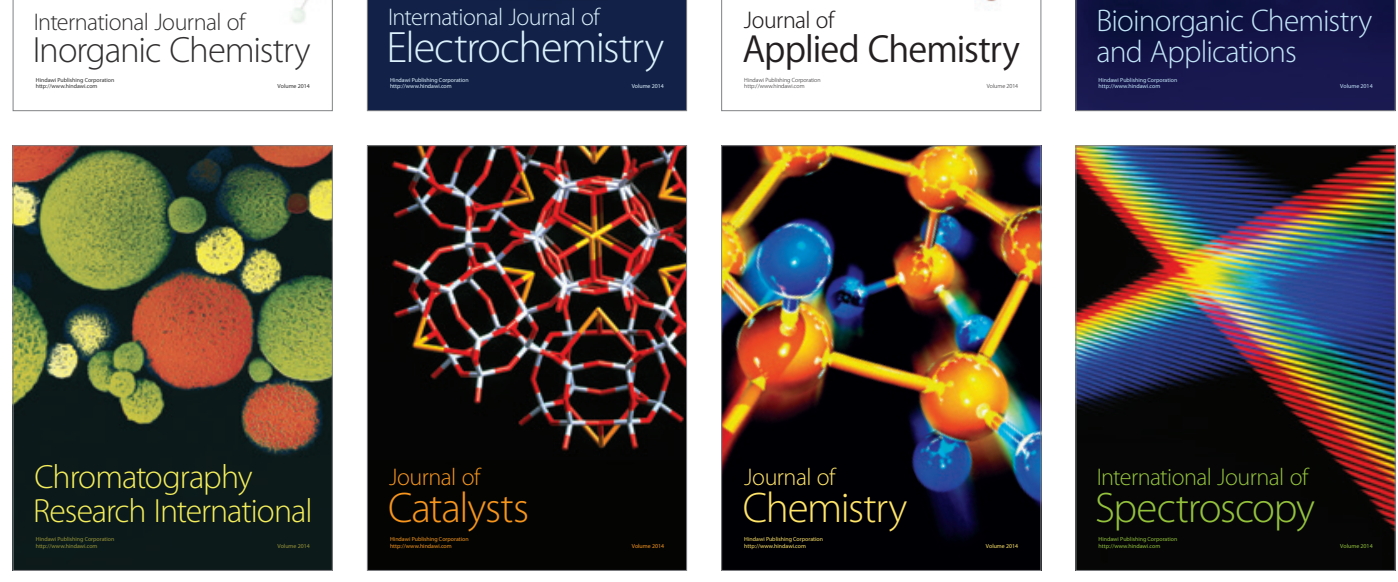